Article

\title{
Effect of Various Temperatures on Bletillae Rhizoma Polysaccharide Extraction and Physicochemical Properties
}

\author{
Xiaoyan Long *, Quan Yan, Linwei Peng, Xinyue Liu and Xuegang Luo \\ School of Life Science and Engineering, Southwest University of Science and Technology, \\ Mianyang 621010, China; yq1275377019@163.com (Q.Y.); penlinwei111@163.com (L.P.); \\ 18681668417@163.com (X.L.); Xuegang9100@sina.com (X.L.) \\ * Correspondence: longxiaoyan@swust.edu.cn
}

Received: 18 October 2018; Accepted: 22 December 2018; Published: 30 December 2018

\begin{abstract}
Six fractional polysaccharides were prepared by water extraction and alcohol precipitation under controlled temperature from bletillae rhizoma, a traditional Chinese medicine. Based on this, yields of bletillae rhizome polysaccharides (RBPs) were obtained. The extracting temperature impacted the characteristics of the fractional polysaccharides. The fractional polysaccharides were characterized by glucomannan (GM) content, thermal stability, scanning electron microscopy (SEM), Fourier-transform infrared (FTIR) spectroscopy, gel permeation chromatography (GPC), and X-ray diffraction (XRD). For the analysis, $2.0 \% w / v$ dispersions of the six fractional polysaccharides were prepared and their flow behaviors were evaluated using a rotational rheometer. The results showed that increased extraction temperature led to increased GM extraction yields and extraction rate, but GM content was relative stable (over 90\%). The average molecular weight $(\mathrm{Mw})$ of fractional polysaccharides obtained at 30,40,50,60,70, and $80^{\circ} \mathrm{C}$ was $3.598 \times 10^{4}, 4.188 \times 10^{4}, 8.632 \times 10^{4}$, $8.850 \times 10^{4}, 2.372 \times 10^{5}$, and $3.081 \times 10^{5} \mathrm{~g} / \mathrm{mol}$, respectively. SEM revealed that fractional polysaccharides had a porous structure of different sizes and densities. Thermal analysis, FTIR, and XRD results indicated that extraction temperature affects the structure and moisture content of fractional polysaccharides. All results showed that the extraction temperature has an obvious impact on the morphology, molecular weight, and polydispersity of the RBPs. This simple process is a promising method for the preparation of fractional polysaccharides.
\end{abstract}

Keywords: bletillae rhizome; fractional polysaccharides; molecular weight; temperature

\section{Introduction}

Polysaccharides collected from biomass continue to attract the attention of researchers due to their apparent advantages, such as low cost, biocompatibility, and nontoxicity [1-3]. They have many uses in the pharmaceutic field and the food and chemical industries as thickeners, binders, and gels, since they can form high-viscosity solutions in aqueous systems [4,5].

Bletillae rhizome, or bai ji, which is the dried tuber of Bletilla striata (Thunb. Reichb.f.), is a kind of traditional medicine material originally documented in Chinese medical classics such as the Shen Non Ben Cao Ging [6]. It has been used as an astringent hemostatic medicine, and is widely used in Eastern Asian countries to treat alimentary canal mucosal damage, tuberculosis, ulcers, hemorrhoids, bleeding, bruises, and burns [7]. The backbone of polysaccharides from bletillae rhizome (RBP) is mainly composed of $(1 \rightarrow 2)$-linked $\alpha$-D-mannopyranose and $(1 \rightarrow 4)$-linked $\beta$-D-glucopyranose residues [8]. RBPs have attracted attention due to their biological activity, such as antioxidant properties $[9,10]$, wound healing [11], and promotion of endothelial cell proliferation and vascular endothelial growth factor expression in vitro [12]. 
Polysaccharides have various functions due to their complicated structure and different molecular weights. Not all RBPs have biological activity, nor do all RBPs have the same biological activity, thus the study of fractional polysaccharides is important. For example, RBP with a molecular weight of $2.35 \times 10^{5}$ Da significantly induced spleen cell proliferation in a dose-dependent manner [13]. RBP with a higher molecular weight does not biodegrade easily in the stomach, and can be used for gastroretentive drug delivery. Therefore, a simple process for the preparation of fractional RBP still needs to be developed; in addition, extraction temperature has a huge effect on the physicochemical properties of materials [14]. At present, there is little research on the effect of temperature on the physicochemical properties of RBP. Due to the potential application of RBP as a biological macromolecule material in pharmaceuticals, foods, and cosmetics, the objective of this paper is to investigate the influence of temperature on the extraction and physicochemical characteristics of RBPs.

\section{Materials and Methods}

\subsection{Materials}

Commercial bletillae rhizoma drugs purchased from local Chinese herbal medicine shops in Mianyang City, China, were milled and the resultant powder sieved (450 $\mu \mathrm{m}$ aperture) to prepare crude bletillae rhizoma flour (RBF). All chemicals were analytical grade and were used as obtained without any further purification. The reagent 3, 5-dinitrosalicylic acid (3,5-DNS) was prepared according to the literature [15].

\subsection{Extraction of Fractional RBP from $R B F$}

Ten grams of RBF was stirred in $400 \mathrm{~mL}$ of pure water for $1 \mathrm{~h}$ at 6 different temperatures (30, 40, 50, 60, 70, and $80^{\circ} \mathrm{C}$ ) and centrifuged at $3000 \mathrm{rpm}$ for $10 \mathrm{~min}$ (RR22GIII High-Speed Refrigerated Centrifuge, Hitachi) to remove insoluble materials. The insoluble residues were treated again twice, as mentioned above. The supernatants were collected and concentrated to $20 \mathrm{~mL}$ by a rotary evaporator (RE-52AA, Yarong Biochemical Instrument Factory, Shanhai, China) at $80{ }^{\circ} \mathrm{C}$ under a vacuum. The concentrated solutions were precipitated with dehydrated ethanol to a final concentration of $70 \%(v / v)$ and incubated for $12 \mathrm{~h}$ at $4{ }^{\circ} \mathrm{C}$. The polysaccharide precipitate was collected by centrifuging at $3000 \mathrm{rpm}$ for $10 \mathrm{~min}$ (RR22GIII High-Speed Refrigerated Centrifuge, Hitachi, Japan) and lyophilized to obtain the polysaccharides. The dried polysaccharide samples were milled and stored in a glass vacuum desiccator at room temperature and coded according to the extracted temperature as RBP30, RBP40, RBP50, RBP60, RBP70, RBP80, and RBF (native). The RBP yield (\%) from the extraction was calculated by the following equation:

$$
\text { RBP yield }(\%)=\frac{\text { weight of dried polysaccharide }(\mathrm{g})}{\text { weight of sample }(\mathrm{g})} \times 100
$$

\subsection{Glucomannan Content Analysis}

Determining GM content by 3,5-DNS has been reported to be the most reliable and accurate method for the colorimetric analysis of konjac glucomannan [15]. The concentration of GM in the solution was assayed by UV-visible spectroscopy (U-3900H, Hitachi, Japan) at $550 \mathrm{~nm}$ using a standard glucose curve of known concentrations in the range of 9.68-77.44 $\mu \mathrm{g} / \mathrm{mL}\left(R^{2}=0.9993\right)$. All tests were done in triplicate, and the percentage of GM was calculated by Equation (2):

$$
\text { GM content }(\%)=\frac{625 \times\left(5 \times T-T_{0}\right)}{M}
$$

where $T$ is the glucose content of sample hydrolysate $(\mathrm{mg}), T_{0}$ is the glucose content of sample extraction (mg), 625 and 5 are the diluting factors, and $M$ is the mass of the sample (about $100 \mathrm{mg}$ ). 


\subsection{Rheological Properties}

To measure the rheological properties, $2.0 \%(w / v)$ water dispersions of extracted RBPs were prepared by carefully dispersing the dispersions in pure water at $500 \mathrm{rpm}$ and $80{ }^{\circ} \mathrm{C}$ for $2 \mathrm{~h}$. The rheological properties were measured by a rheometer (HAAKE MARS II, Thermo Scientific, Germany). The measurement module had cone-plate geometry (cone diameter $60 \mathrm{~mm}$, angle $1^{\circ}$ ). The gap between the plate and the cone was $0.052 \mathrm{~mm}$ and set automatically. All measurements were carried out at $25.0 \pm 0.05^{\circ} \mathrm{C}$. Each measurement was repeated three times. Samples were sheared continuously at a rate ranging from 0.01 to $200 \mathrm{~s} \mathrm{~s}^{-1}$ in 120 seconds. The shear stress $(\tau)$ versus shear rate $(\dot{\gamma})$ data were fitted by using the Ostwald-de Waele model (Equation (3)) [16] or the non-Newtonian law of viscosity (Equation (4)):

$$
\begin{aligned}
\tau & =k \cdot \dot{\gamma}^{n} \\
\tau & =\eta \cdot \dot{\gamma}
\end{aligned}
$$

where $k$ is the consistency coefficient $\left(\mathrm{mPa} s^{n}\right)$ and $n$ is the flow behavior index (dimensionless).

\subsection{Gel Permeation Chromatography (GPC) Analysis}

A given amount of RBPs (50 mg) was added to $10 \mathrm{~mL}$ of eluent (a mixture of $0.01 \% \mathrm{NaNO}_{3}$ and $0.02 \% \mathrm{NaN}_{3}$ ) by vigorous agitation, then the RBP solution was filtered by a $0.45 \mu \mathrm{m}$ filter (micro PES) in turn. The samples were then determined by gel permeation chromatography with multiangle laser light scatter $\left(\lambda=609.0 \mathrm{~nm}, \mathrm{~T}=35^{\circ} \mathrm{C}\right.$; DAWN-EOS multiangle laser photometer, Wyatt Technology Co., Goleta, CA, USA) equipped with a pump (Agilent G1310 A) under the following conditions: flow rate: $0.5 \mathrm{~mL} \mathrm{~min}^{-1}$; chromatographic column: aqueous SEC Start-up Kit, $300 \mathrm{~mm} \times 7.5 \mathrm{~mm}$ (Agilent). The refractive index increment $(\mathrm{dn} / \mathrm{dc})$ of RBPs was 0.1402 .

\subsection{Scanning Electron Microscopy Analysis}

The morphological features of RBPs were determined using a TM-3000 scanning electron microscope at an accelerating voltage of $15 \mathrm{kv}$ during micrography (Ultra55, Zeiss, Germany). The test RBPs were dispersed on a specimen holder with the aid of double-sided carbon tape and then sputtered with gold for $180 \mathrm{~s}$ using a sputter coater (SBC7620, Emitech, Great Britain).

\subsection{Thermogravimetric (TG) Analysis}

TG experiments of RBPs were conducted on a Q500 TGA thermogravimeteric analyzer (TA, USA). The samples weighed 5 to $10 \mathrm{mg}$ and were placed in the platinum pan sample holder. RBPs were heated and weight loss was recorded from room temperature to $550{ }^{\circ} \mathrm{C}$ at a heating rate of $10^{\circ} \mathrm{C} / \mathrm{min}$ under a nitrogen atmosphere.

\subsection{Differential Scanning Calorimetry (DSC) Analysis}

DSC of RBPs was performed using a DSC Q200 (TA, USA) apparatus. RBPs samples (3-6 mg) were weighed on an aluminum pan, then the pan was sealed. The heat capacity was scanned from $40-200{ }^{\circ} \mathrm{C}$ at a constant rate of $10^{\circ} \mathrm{C} / \mathrm{min}$ and an air speed of $10^{\circ} \mathrm{C} / \mathrm{min}$ in a nitrogen atmosphere.

\subsection{Fourier-Transform Infrared (FTIR) Spectroscopy Analysis}

FTIR spectroscopy of RBPs was conducted using the potassium bromide disc method on a Nicolet 6700 FTIR spectrometer in the range of $4000-400 \mathrm{~cm}^{-1}$, with a resolution of $4 \mathrm{~cm}^{-1}$.

\subsection{X-ray Diffraction (XRD) Analysis}

XRD of RBPs was conducted by using an X-ray diffractometer (PANalytical, Holland). The operating conditions were as follows: nickel-filtered $\mathrm{Cu} K \alpha$ radiation, $40 \mathrm{kV}, 40 \mathrm{~mA}$, scan speed 
$5^{\circ} \mathrm{min}^{-1}$. The angle of diffraction was changed from $5^{\circ}$ to $90^{\circ}$ to identify any changes in the crystal structure.

\subsection{Elemental Analysis}

The obtained RBPs were analyzed for their carbon, hydrogen, nitrogen, and sulfur content using the elemental EL cube. The remaining parts of the samples were assumed to be oxygen. The protein content of RBPs was estimated from the nitrogen content of the biopolymers by multiplying the obtained experimental values by 6.25 .

\section{Results and Discussion}

\subsection{GM Content, Yield, and Extraction Rate Analysis of Fractional RBPs}

For use, the prepared crude bletillae rhizoma flour (RBF) should be purified. It was purified by water extraction and alcohol precipitation under controlled temperature to give the pure polysaccharide fraction RBP. We then studied the GM content, yield, and extraction rates of RBP30, RBP40, RBP50, RBP60, RBP70, and RBP80, and the results are presented in Table 1. The results show that the GM content of all RBPs increased significantly compared with RBF $(p<0.05)$. However, GM content decreased as the temperature reached $50{ }^{\circ} \mathrm{C}$, but then increased again as the temperature rose. The maximum value $\left(94.67 \%\right.$ ) was obtained at the extraction temperature of $70{ }^{\circ} \mathrm{C}$. Although there was no remarkable difference in GM content among all RBPs, the yield ranged between $47.47 \%$ and $54.35 \%$, and the extraction rate ranged from $74.60 \%$ to $85.37 \%$ when the temperature was increased from 30 to $80^{\circ} \mathrm{C}$. It is apparent that higher extraction temperatures increase the dissolution of the RBF ingredients, resulting in higher yield. These findings are consistent with the previously observed extraction of corn silk polysaccharides [13].

\subsection{Rheological Properties of Fractional RBPS}

The flow curves of 2.0\% (w/v) aqueous solutions of the six fractional RBPs are shown in Figure 1. At the same shear rate, the shear stress of fractional RBP solution increased with increasing extraction temperature. Newtonian behavior of fractional RBP solutions (RBP30, RBP40, RBP50, and RBP60) extracted under low temperature $\left(30-60^{\circ} \mathrm{C}\right)$ was observed. Non-Newtonian or shear-thinning behavior occurred at high extraction temperatures $\left(70-80^{\circ} \mathrm{C}\right)$, which has been described as typical behavior of many polysaccharides in water dispersion [17]. The RBP70 and RBP80 power regression results fitted by the Ostwald-de Waele model (Equation (3)) $\left(R^{2} \geq 0.999\right)$ are presented as $k$ values of 114 and 264.363 and $n$ values of 0.944 and 0.853 . The $n$ value (flow behavior index) for $2.0 \%$ RBP70 and RBP80 solutions was lower than 1, which also suggests that the two fractional RBPs are pseudoplastic. The pseudoplastic nature of RBP70 and RBP80 reveals the intermolecular interactions between polymer chains. At low shear rate, molecular chains of RBP70 and RBP80 aqueous solution had random helical conformation with relatively high apparent viscosity, but the induced continuous increase in force may lead to molecular deformation, rod breakage, and consequently a decrease in apparent viscosity [18].

Table 1. Glucomannan (GM) content and yield of RBPs.

\begin{tabular}{ccc}
\hline Sample Code & GM Content (\%) & RBP Yield (\%) \\
\hline RBF & $60.77 \pm 0.02$ & - \\
RBP30 & $93.82 \pm 0.82^{\mathrm{a}}$ & $47.47 \pm 0.42$ \\
RBP40 & $93.29 \pm 0.43^{\mathrm{a}}$ & $49.31 \pm 0.95$ \\
RBP50 & $92.88 \pm 0.38^{\mathrm{a}}$ & $50.28 \pm 0.58^{\mathrm{b}}$ \\
RBP60 & $93.10 \pm 0.84^{\mathrm{a}}$ & $51.31 \pm 0.95^{\mathrm{b}}$ \\
RBP70 & $94.67 \pm 1.29^{\mathrm{a}}$ & $53.20 \pm 0.68^{\mathrm{b}}$ \\
RBP80 & $94.58 \pm 0.80^{\mathrm{a}}$ & $54.35 \pm 0.72^{\mathrm{b}}$
\end{tabular}

a Significance (level 0.05) compared to RBF within the same column; ${ }^{\mathrm{b}}$ significance (level 0.05) compared to RBP30 within the same column. 

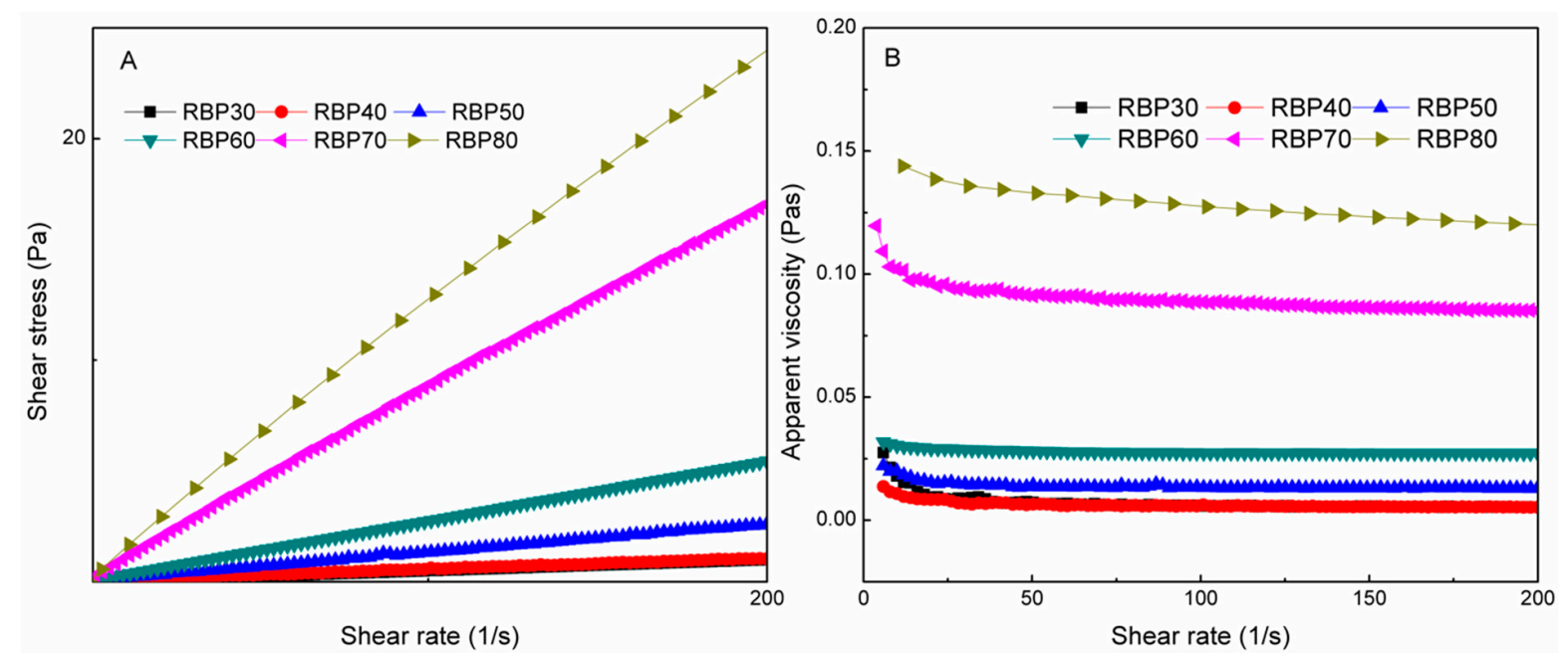

Figure 1. (A) Shear stress and (B) apparent viscosity of $2.0 \%(w / v)$ aqueous solutions of six fractional bletillae rhizome polysaccharides (RBPs) as a function of shear rate at $25^{\circ} \mathrm{C}$.

Apparent viscosity levels were affected by molecular weight [19]. Changes in apparent viscosity can be used to monitor the interaction between polysaccharide or conformational changes of components in aqueous solutions [20]. Temperature has a greater influence on the apparent viscosity of fractional RBPs. Figure 2 shows a relationship between the apparent viscosity of $2.0 \%$ aqueous solution of the six fractional RBPs at a shear rate of $10 \mathrm{~s}^{-1}$ and the extraction temperature. It was clear that the apparent viscosity followed an increasing trend as temperature increased. RBP70 and RBP80 had far higher apparent viscosity than RBP30, RBP40, RBP50, and RBP60. As shown in Table 1, although the GM content of both RBP30 and RBP80 was $94 \%$, the apparent viscosity of $2.0 \%(w / v)$ aqueous solution of RBP30 and RBP80 differed. RBP80 had the highest viscosity increment, about eight times that of RBP30. This phenomenon can be explained by the fact that high extraction temperature facilitates the diffusion of high-molecular-weight RBP out of the cells, which results in increased entanglement density of high-molecular-weight polysaccharides. The results agree well with the GPC results.

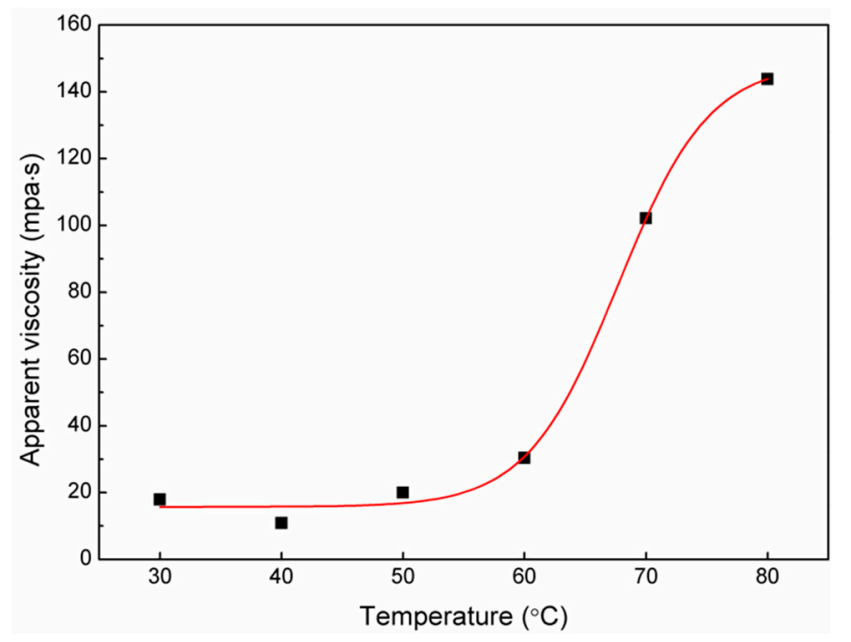

Figure 2. Dependence of extraction temperature of apparent viscosity of RBPs at $10 \mathrm{~s}^{-1}, C_{R B P}$, was $2.0 \mathrm{wt} \%$.

It is very important to develop a good model description of the effects of extraction temperature on the apparent viscosity of fractional RBP solutions to accurately predict the performance of the temperature (T)-apparent viscosity (AV) process. The apparent viscosity of fractional RBP solutions was used at a shear rate of $10 \mathrm{~s}^{-1}$. The obtained results are plotted in Figure 2. The apparent viscosity 
of fractional RBPs extracted over $70{ }^{\circ} \mathrm{C}$ was greatly improved. As visualized in Figure 2, T-AV curves were perfectly fitted with the dose-response equation $\left(R^{2}=0.9936\right)$ (Equation (5)):

$$
\mathrm{AV}=15.8188+\frac{131.68}{1+10^{(67.16-T)^{0.12}}}
$$

The result indicates that temperature control is a key factor in RBF fractional polysaccharide extraction. The dose-response equation offers an option for simulating the temperature-apparent viscosity of the fractional RBP process.

\subsection{GPC Analysis}

The molecular weight of polymer is important information to understand its application [21]. Molecular weights of RBPs were detected by GPC-Multi-Angle Laser Light Scattering (MALLS) (Figure 3A) and GPC-differential refractive index (DRI) (Figure 3B)). The experimental results are shown in Table 2. The extraction temperature had a great influence on the molecular weight of RBPs. Both $\mathrm{Mw}$ and $\mathrm{Mn}$ increased with increased extraction temperature. According to Figure 3A,B, increasing the extraction temperature resulted in decreased RBP retention time $\left(\mathrm{R}_{\mathrm{T}}\right)$. Compared to RBP treated under lower extraction temperature (RBP30, $\mathrm{Mw}=3.598 \times 10^{4} \mathrm{~g} / \mathrm{mol}$ ), the molecular weight of RBP treated under higher extraction temperature (RBP80, Mw $=3.081 \times 10^{5} \mathrm{~g} / \mathrm{mol}$ ) was larger by about 8.56 -fold. It was inferred that the obvious increase in particle size under higher extraction temperature could decrease the porosity and capillary attraction of RBP and consequently enhance its physical entrapment.
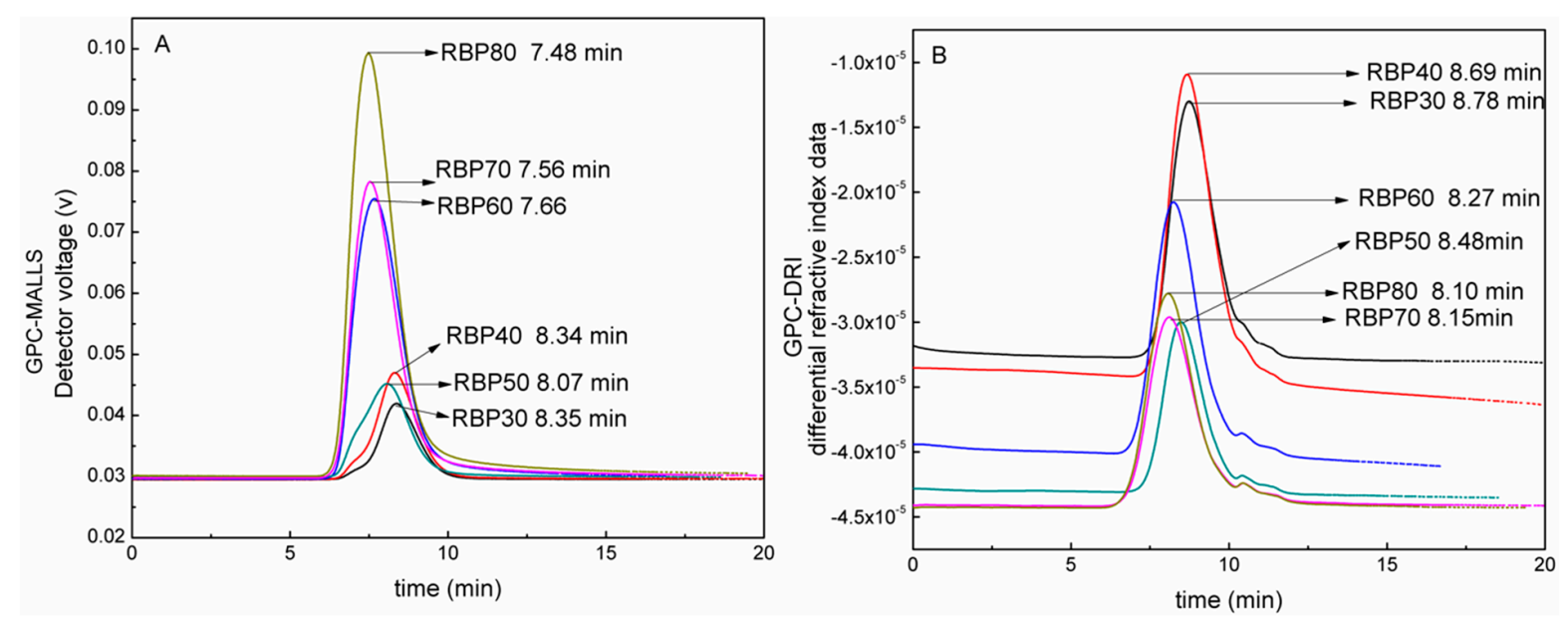

Figure 3. Gel permeation chromatography (GPC) analysis of RBPs.

Table 2. Molecular weight and polydispersity index of RBPs.

\begin{tabular}{|c|c|c|c|c|c|c|}
\hline Sample & RBP30 & RBP40 & RBP50 & RBP60 & RBP70 & RBP80 \\
\hline $\begin{array}{c}\text { MALLS R } \\
\text { (min) }\end{array}$ & 8.35 & 8.34 & 8.07 & 7.66 & 7.56 & 7.48 \\
\hline $\begin{array}{c}\text { DRI R R } \\
(\mathrm{min})\end{array}$ & 8.78 & 8.69 & 8.48 & 8.27 & 8.15 & 8.1 \\
\hline $\mathrm{Mw}(\mathrm{g} / \mathrm{mol})$ & $3.598 \times 10^{4}$ & $4.188 \times 10^{4}$ & $8.632 \times 10^{4}$ & $8.850 \times 10^{4}$ & $2.372 \times 10^{5}$ & $3.081 \times 10^{5}$ \\
\hline $\mathrm{Mn}(\mathrm{g} / \mathrm{mol})$ & $2.539 \times 10^{4}$ & $2.672 \times 10^{4}$ & $5.263 \times 10^{4}$ & $5.181 \times 10^{4}$ & $1.387 \times 10^{5}$ & $1.767 \times 10^{5}$ \\
\hline $\mathrm{D}$ & 1.417 & 1.567 & 1.64 & 1.708 & 1.711 & 1.744 \\
\hline
\end{tabular}

Molecular weight distribution ( $\mathrm{D}, \mathrm{Mw} / \mathrm{Mn}$ ) was used to characterize polydispersion. The greater the value of $\mathrm{D}$, the more dispersed the molecular weight [5]. According to Table 2, the extraction temperature had a great influence on the molecular weight distribution of RBFs. Molecular weight 
(Mn) and D showed corresponding changes with $\mathrm{Mw}$, which showed that RBP from RBF under high extraction temperature had broad polydispersity. Polysaccharides are polydispersed polymers in natural polymers. The properties and activities of polysaccharides are related to their molecular weight distribution.

\subsection{Morphology of RBPs}

To study the surface morphology of polysaccharide, SEM has been a tool of choice reported in many studies [22]. Figure 4 shows SEM pictures of RBP30-RBP80. The porous structure of all RBPs can be seen. RBP30, extracted at $30^{\circ} \mathrm{C}$, has a pore size (about $500 \mathrm{~nm}$ ) that is three times that of RBP80, which was extracted at $80^{\circ} \mathrm{C}$. Their pore diameters decreased with increasing extraction temperature. The result indicates that extraction temperature has a certain relationship with porous structure. The electron micrograph in Figure 5 shows that RBPs extracted at lower temperatures can easily generate porous structure, which enhances the capillary action and inner-surface area that are beneficial to water absorption [23]. RBP80, which was extracted at higher temperature, presented a layered integrity structure, possibly due to the interaction between polysaccharide molecules. The surface of the layers had small pores of about $150 \mathrm{~nm}$ diameter. Biopolymers with complete structures and smooth surfaces can be used as membranes and drug delivery system candidates [24], so RBP80 is a good candidate for the preparation of membranes and biopolymer-based drug delivery systems. The results further confirmed that high extraction temperature results in high-molecular-weight polysaccharide from RBF.
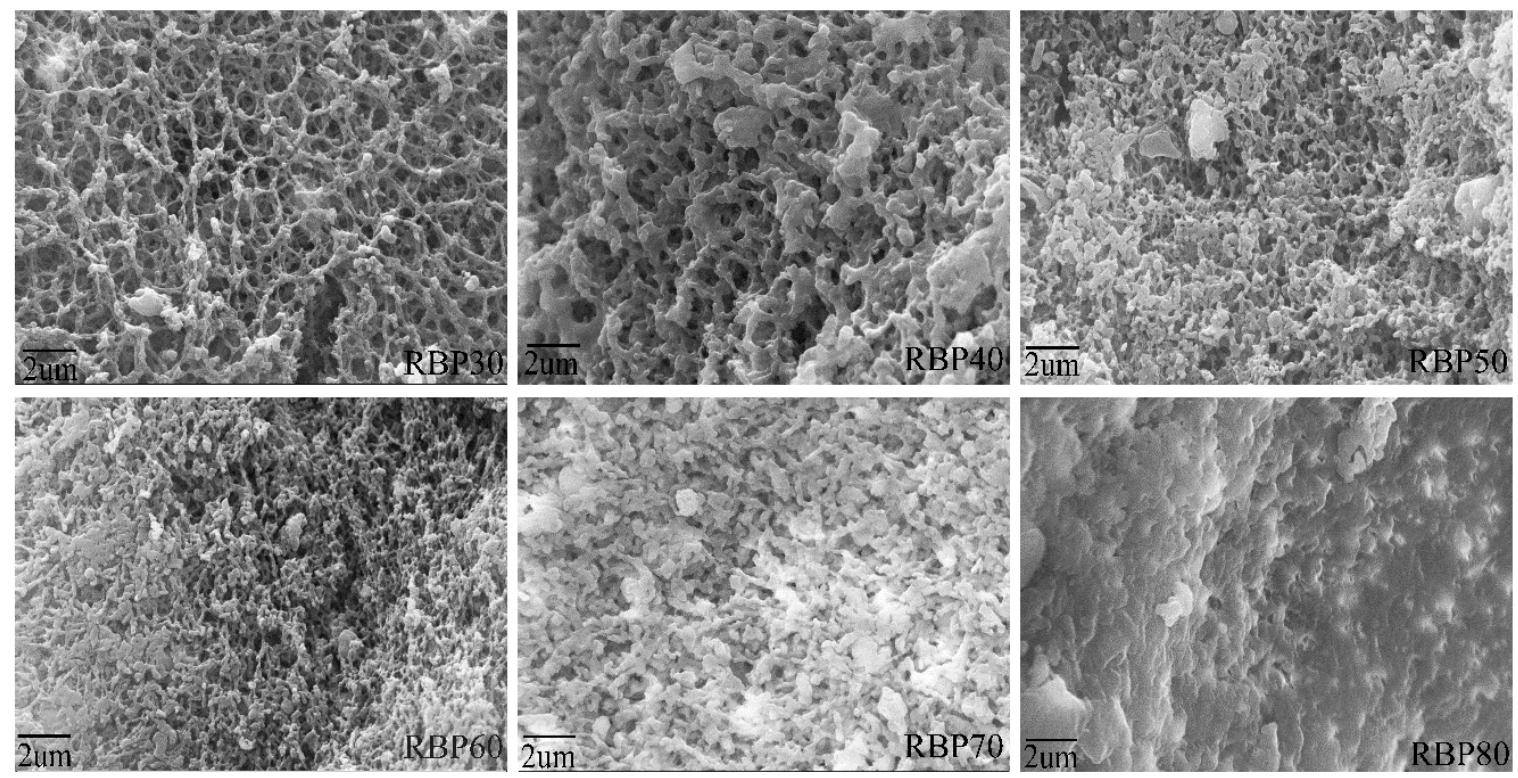

Figure 4. SEM images of RBPs extracted at different temperatures.

\subsection{Thermal Analysis}

Thermogravimetric analysis (TGA) and DSC have been widely applied as the main methods of evaluating thermal stability of materials for many years. Thermal stability analysis for RBPs was performed by TGA and DSC, and the results are shown in Table 3 and Figure 5. The first mass loss stage near $110^{\circ} \mathrm{C}$ was due to the loss of adsorbed water on the RBP surface [5]. A weight loss of 73-88\% after the onset of heat treatment at $280-300{ }^{\circ} \mathrm{C}$ was mainly due to the pyrolysis of RBPs, which was consistent with other polysaccharide studies [11,25]. Figure 5A shows improvement in the thermal stability of RBPs with increased extraction temperature. According to RBP TGA curves, values related to RBP30, RBP40, RBP50, and RBP60 of around $350-550{ }^{\circ} \mathrm{C}$ are lower compared to RBP70 and RBP80. It is well known that the polar moieties in the network may act as heat barriers and consequently enhance the overall thermal stability of RBP70 and RBP80 [26]. Another factor is their macromolecular 
structure. The thermal behavior and GPC of RBPs are provided in Table 3 and Figure 5. The GPC curves show that the maximum peaks of RBP70 and RBP80 (both laser signals and DRI signals) occur earlier than those of RBP30, RBP40, RBP50, and RBP60. According to Table 3, the molecular weight of RBP70 and RBP80 is higher than that of RBP30, RBP40, RBP50, and RBP60.

Table 3. Thermal properties of RBPs.

\begin{tabular}{|c|c|c|c|c|c|c|}
\hline \multirow{3}{*}{ Sample } & \multicolumn{4}{|c|}{ TGA } & \multirow{2}{*}{\multicolumn{2}{|c|}{$\begin{array}{c}\text { DSC } \\
\text { Endothermic Peak }\end{array}$}} \\
\hline & \multirow{2}{*}{$\begin{array}{c}\text { First Mass Loss Stage } \\
\text { Mass Loss }(\%)\end{array}$} & \multicolumn{3}{|c|}{ Second Mass Loss Stage } & & \\
\hline & & Onset Temperature (\%) & DTG $\left({ }^{\circ} \mathrm{C}\right)$ & Mass Loss (\%) & Temperature $\left({ }^{\circ} \mathrm{C}\right)$ & Heat Flow $(\mathrm{W} / \mathrm{g})$ \\
\hline RBP30 & -7.80 & 282.5 & 328.3 & -87.60 & 98.42 & -1.750 \\
\hline RBP40 & -6.83 & 281.2 & 328.5 & -80.76 & 99.34 & -1.539 \\
\hline RBP50 & -8.84 & 296.1 & 333.5 & -77.73 & 106.45 & -1.411 \\
\hline RBP60 & -8.79 & 298.5 & 331.2 & -74.22 & 109.37 & -1.373 \\
\hline RBP70 & -8.69 & 298.3 & 330.8 & -71.74 & 111.88 & -1.299 \\
\hline RBP80 & -7.69 & 295.2 & 327.9 & -72.73 & 118.41 & -1.257 \\
\hline
\end{tabular}

The typical endotherms with peak temperatures of RBPs $\left(98.42-111.88^{\circ} \mathrm{C}\right)$ appeared in the DSC thermograms in Figure 5B, which was due to a loss of hydroxyl group of RBPs as water molecules.

The results are in good agreement with previous TGA results. A shoulder exothermic peak was observed by DSC with an onset temperature of $\sim 155^{\circ} \mathrm{C}$, which signifies the second loss of hydroxyl group of RBPs as water molecules. The reaction is as follows: $\mathrm{RBP}-\mathrm{H}_{2} \mathrm{O} \stackrel{\Delta}{\rightarrow} \mathrm{RBP}+\mathrm{H}_{2} \mathrm{O}$. Endothermic and shoulder exothermic peaks revealed that RBP40 and RBP70 had higher heat flow because of different treatment methods. According to Table 3, the upshift of the peak temperature of RBPs prepared under higher temperatures demonstrates that RBPs with higher molecular weights prepared under higher temperatures were enhanced in comparison with the samples treated under lower temperatures, because short-chain RBPs have strong hydrogen bonds within their junction zones that require more energy to decompose the crystalline structure [22].
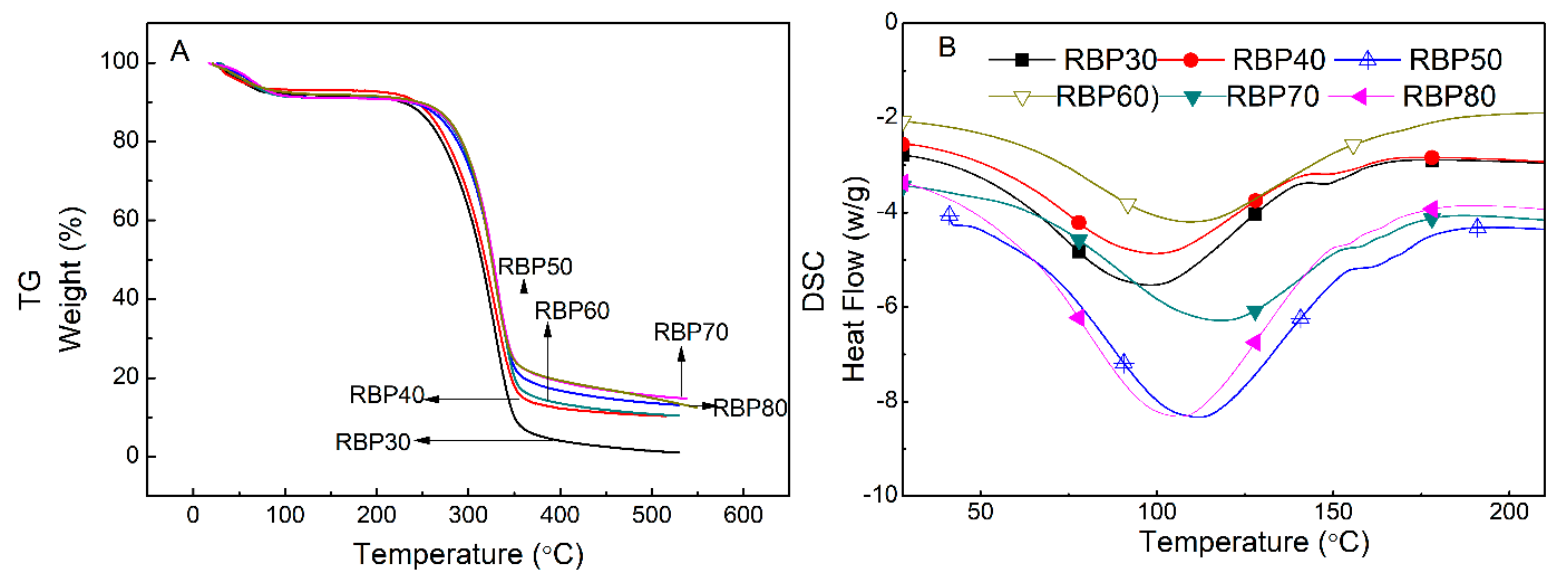

Figure 5. Thermal properties of RBPs.

\subsection{FTIR Spectroscopy}

To further understand the structure of extracted materials from RBF with different temperatures, FTIR spectra of a series of extracted material coded as RBP30, RBP40, RBP50, RBP60, RBP70, and RBP80 were determined, and the results are shown in Figure 6. The spectra revealed that extracted materials from RBF had similar characteristic absorption peaks at 3439, 2931, 2886,1736, 1637, 1380, 1029, 874 , and $813 \mathrm{~cm}^{-1}$, which indicates that the structure did not obviously change with different temperatures. The strong absorptive peak of $3439 \mathrm{~cm}^{-1}$ between the regions $3500-3100 \mathrm{~cm}^{-1}$ is characteristic of a carbohydrate ring featuring a hydroxyl stretching vibration, and showed that there were intermolecular and intramolecular hydrogen bonds $[5,27]$. The peaks in the region of 
$3000-2800 \mathrm{~cm}^{-1}$ absorption at about $2927 \mathrm{~cm}^{-1}$ was assigned to the $\mathrm{C}-\mathrm{H}$ stretching vibration and about $2886 \mathrm{~cm}^{-1}$ asymmetrical stretching vibration [28]. The relatively strong absorption peak at $1736 \mathrm{~cm}^{-1}$ indicated the characteristic $\mathrm{C}=\mathrm{O}$ groups, and the band at $1637 \mathrm{~cm}^{-1}$ to bound water [29]. Each particular polysaccharide has a specific band in the $1200-950 \mathrm{~cm}^{-1}$ region. This represents the fingerprint region for carbohydrates and is dominated by ring vibrations overlapped with stretching vibrations of $\mathrm{C}-\mathrm{OH}$ side groups and $\mathrm{C}-\mathrm{O}-\mathrm{C}$ glycosidic band vibration [30] RBP displayed absorption at $1145 \mathrm{~cm}^{-1}, 1058 \mathrm{~cm}^{-1}$, and $1027 \mathrm{~cm}^{-1}$, which was due to pyranose. In the anomeric region (950-700 $\mathrm{cm}^{-1}$ ), the polysaccharide exhibited obvious characteristic adsorption at $812 \mathrm{~cm}^{-1}$, indicating the glucopyranose units in RBPs [31]. The $\beta$-conformer had absorption peaks near $874 \mathrm{~cm}^{-1}$, and the $\alpha$-conformer region was near $812 \mathrm{~cm}^{-1}$ [8,32]. The characteristic absorption peaks at $812 \mathrm{~cm}^{-1}$ and at nearby $874 \mathrm{~cm}^{-1}$ were observed in the IR spectra of the RBPs, indicating that the sugar units of the polysaccharides were linked not only by $\alpha$-glycosidic bond but also $\beta$-glycosidic bonds. The characterization of six extracted materials by FTIR showed the typical absorption of polysaccharide.

According to report, the narrowing of the wave band is due to the ordering of polymers [33]. The narrowing band in the region $3500-3000 \mathrm{~cm}^{-1}$ was seen for RBP80, RBP70, and RBP40, in that order, indicating ordering of polysaccharide chains due to the changed extraction temperature. RBP40, with the narrowest band in the region, $3500-3000 \mathrm{~cm}^{-1}$, had the highest degree of crystallinity (Figure 7). These observations are in line with the XRD data, confirming that the aggregation structures were changed by different extraction temperatures.

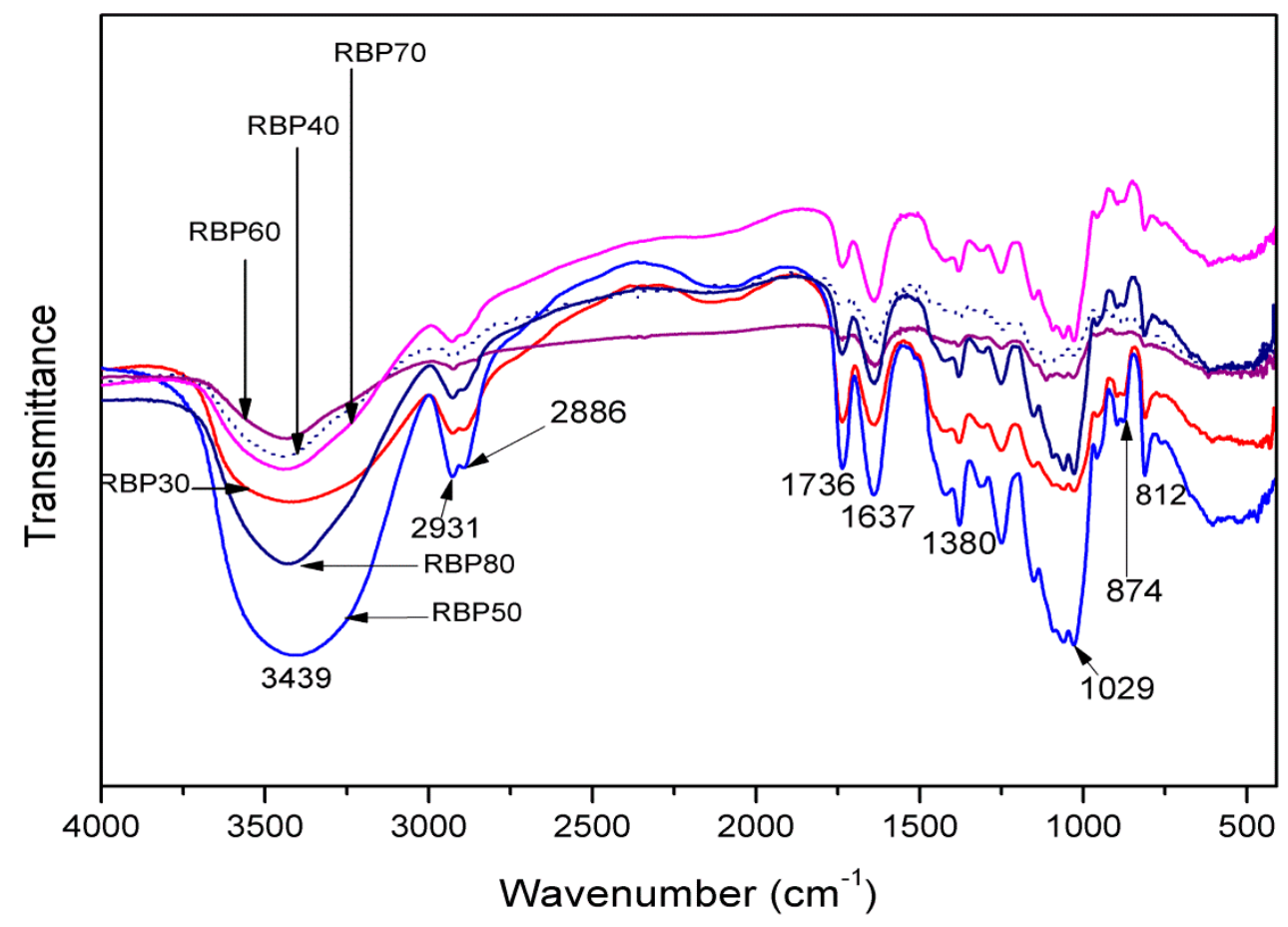

Figure 6. FTIR spectra of RBPs.

\subsection{X-ray Diffraction}

X-ray diffraction measurements were performed to check whether temperature altered the aggregation structures of RBPs, and the XRD patterns are shown in Figure 7. No sharp peaks can be observed, showing that the RBPs are semicrystalline material under $30-80^{\circ} \mathrm{C}$ [5]. All RBPs showed diffusion peaks at about $2 \theta$ of around $20.4^{\circ}$ over the $2 \theta$ range from $7^{\circ}$ to $31^{\circ}$. Similar results were observed for salep glucomannan, with a characteristic peak at $2 \theta$ of around $20.4^{\circ}$ [14]. Comparing the patterns, RBP60 and RBP70 had greater intensity than the other RBPs and showed a large crystalline state. The pattern of RBP80 showed a weak diffusion peak at around $38.8^{\circ}$ over the $2 \theta$ range from $31^{\circ}$ to $52^{\circ}$ with increased extraction temperature, which suggests another degree of crystallinity. The X-ray 
diffraction indicated that with different temperatures, the aggregation structures of RBPs were changed, and the hydrogen bonding of RBP60, RBP70, and RBP80 was weakened.

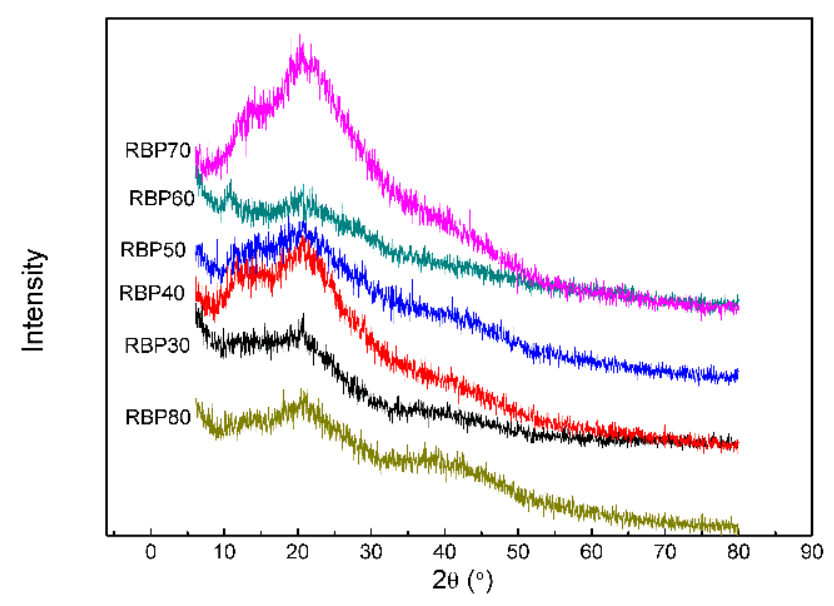

Figure 7. XRD curves of RBPs.

\subsection{Elemental Analysis}

The results of elemental analysis clearly reveal the element contents of RBP30, RBP40, RBP50, RBP60, RBP70, and RBP80 (Table 4). Sulfur was not detected as a constituent. The mass percentage of $\mathrm{C}$ in the prepared fractional polysaccharides had tiny changes. However, the mass percentage of $\mathrm{N}$ gradually decreased from $0.33 \%$ in RBP30 to 0.17 in RBP80, and the mass percentage of $\mathrm{H}$ gradually increased from $7.16 \%$ in RBP30 to 7.99 in RBP80. All RBPs contained little nitrogen content, which demonstrated protein in the six fractional polysaccharides. The protein content of RBPs was estimated from the amount of nitrogen (protein content $\%=N \% \times 6.25$ ) and fell within $3 \%$. The effective reduction of protein content indicated that there was no need for an additional deproteinization procedure, e.g., via the Sevag method or alkaline protease.

Table 4. Elemental analysis of RBPs composites.

\begin{tabular}{ccccc}
\hline \multirow{2}{*}{ Sample } & \multicolumn{3}{c}{ Mass Percentage, wt $\%$} & \multirow{2}{*}{ Protein Content (\%) } \\
\cline { 2 - 4 } & $\mathbf{C}$ & $\mathbf{N}$ & $\mathbf{H}$ & \\
\hline RBP30 & 40.33 & 0.33 & 7.16 & 2.05 \\
RBP40 & 40.22 & 0.30 & 7.17 & 1.89 \\
RBP50 & 40.15 & 0.29 & 7.21 & 1.82 \\
RBP60 & 40.45 & 0.29 & 7.25 & 1.79 \\
RBP70 & 40.19 & 0.26 & 7.33 & 1.63 \\
RBP80 & 40.57 & 0.17 & 7.99 & 1.06 \\
\hline
\end{tabular}

\section{Conclusions}

From the results obtained in our study, we can conclude that the fractional polysaccharides from bletillae rhizome (RBP30-80) could be prepared by water extraction and alcohol precipitation under controlled temperature. The temperature had little effect on the glucomannan content and FTIR spectroscopy of RBPs, but their rheological properties and thermal properties changed remarkably. GPC revealed that the water extraction and alcohol precipitation processes under higher temperatures resulted in products with higher $\mathrm{Mw}, \mathrm{Mn}$, and PdI of fractional RBP. The thermal behavior suggested that RBPs treated by higher temperatures had higher stability than RBPs treated by lower temperatures. The morphology of RBPs confirmed that temperature resulted in a significant difference between RBP30 and RBP80. Fractional polysaccharides from XRD of bletillae rhizome prepared under higher temperatures showed high crystallinilty. The results of this study could be useful in expanding the 
application of RBPs. Further exploration of fractional RBPs should focus on fractional polysaccharide biological activity.

Author Contributions: X.L. (Xiaoyan Long) and X.L. (Xuegang Luo) conceived and designed the experiments; Q.Y., X.L. (Xinyue Liu) and L.P. performed the experiments; X.L. (Xiaoyan Long) analyzed the data.

Funding: This work was funded by the PhD fellowship of Southwest University of Science and Technology, grant number 15zx7119; the Mianyang Science and Technology Agency Basic Project, Sichuan Province, China, grant number 17YFNY008); and the Longshan Academic Talent Research Supporting Program of SWUST, Sichuan Province, China, grant number 17LZX547, 18LZX537.

Acknowledgments: The authors acknowledge Engineering Research Center of Biomass Materials, Ministry of Education, Mianyang, China for analytical support.

Conflicts of Interest: The authors declare no conflicts of interest.

\section{References}

1. Ke, Y.; Wu, Y.; Cui, X.; Liu, X.; Yu, M.; Yang, C.; Li, X. Polysaccharide Hydrogel Combined with Mesenchymal Stem Cells Promotes the Healing of Corneal Alkali Burn in Rats. PLoS ONE 2015, 10, e0119725. [CrossRef] [PubMed]

2. Luo, Y.; Diao, H.; Xia, S.; Dong, L.; Chen, J.; Zhang, J. A physiologically active polysaccharide hydrogel promotes wound healing. J. Biomed. Mater. Res. Part A 2010, 94A, 193-204. [CrossRef] [PubMed]

3. Perez-Moral, N.; Gonzalez, M.C.; Parker, R. Preparation of iron-loaded alginate gel beads and their release characteristics under simulated gastrointestinal conditions. Food Hydrocoll. 2013, 31, 114-120. [CrossRef]

4. Han, M.; Du, C.; Xu, Z.-Y.; Qian, H.; Zhang, W.-G. Rheological properties of phosphorylated exopolysaccharide produced by Sporidiobolus pararoseus JD-2. Int. J. Biol. Macromol. 2016, 88 (Suppl. C), 603-613. [CrossRef] [PubMed]

5. Kong, L.; Yu, L.; Feng, T.; Yin, X.; Liu, T.; Dong, L. Physicochemical characterization of the polysaccharide from Bletilla striata: Effect of drying method. Carbohydr. Polym. 2015, 125, 1-8. [CrossRef]

6. Wu, T.-Y.; Lay, H.-L. Effect of growth stages, culture media, and processing methods on the component variations of Bletilla formosana and comparison of its component contents to commercial Rhizoma Bletillae crude drugs. J. Food Drug Anal. 2013, 21, 404-413. [CrossRef]

7. Dong, L.; Xia, S.; Luo, Y.; Diao, H.; Zhang, J.; Chen, J.; Zhang, J. Targeting delivery oligonucleotide into macrophages by cationic polysaccharide from Bletilla striata successfully inhibited the expression of TNF-alpha. J. Control. Release 2009, 134, 214-220. [CrossRef]

8. Wang, Y.; Liu, D.; Chen, S.J.; Wang, Y.; Jiang, H.X.; Yin, H.P. A new glucomannan from Bletilla striata: Structural and anti-fibrosis effects. Fitoterapia 2014, 92, 72-78. [CrossRef]

9. Qu, Y.; Li, C.; Zhang, C.; Zeng, R.; Fu, C. Optimization of infrared-assisted extraction of Bletilla striata polysaccharides based on response surface methodology and their antioxidant activities. Carbohydr. Polym. 2016, 148, 345-353. [CrossRef]

10. Yoon, J.H.; Park, S.G.; Lee, M.J.; Park, J.Y.; Seo, K.S.; Woo, K.C.; Lee, C.E. Antioxidant and Anti-inflammatory Effects of Bletilla striata Reichenbach fil. Fractions as Cosmetic. J. Life Sci. 2013, 23. [CrossRef]

11. Urrutia, P.; Bernal, C.; Escobar, S.; Santa, C.; Mesa, M.; Wilson, L.; Illanes, A. Influence of Chitosan Derivatization on Its Physicochemical Characteristics and Its Use as Enzyme Support. J. Appl. Polym. Sci. 2014, 131. [CrossRef]

12. Wang, C.; Sun, J.; Luo, Y.; Xue, W.; Diao, H.; Dong, L.; Chen, J.; Zhang, J. A polysaccharide isolated from the medicinal herb Bletilla striata induces endothelial cells proliferation and vascular endothelial growth factor expression in vitro. Biotechnol. Lett. 2006, 28, 539-543. [CrossRef] [PubMed]

13. Maran, J.P.; Manikandan, S.; Thirugnanasambandham, K.; Nivetha, C.V.; Dinesh, R. Box-Behnken design based statistical modeling for ultrasound-assisted extraction of corn silk polysaccharide. Carbohydr. Polym. 2013, 92, 604-611. [CrossRef] [PubMed]

14. Kurt, A.; Kahyaoglu, T. Purification of glucomannan from salep: Part 2. Structural characterization. Carbohydr. Polym. 2017, 169, 406-416. [CrossRef] [PubMed]

15. Chua, M.; Chan, K.; Hocking, T.J.; Williams, P.A.; Perry, C.J.; Baldwin, T.C. Methodologies for the extraction and analysis of konjac glucomannan from corms of Amorphophallus konjac K. Koch. Carbohydr. Polym. 2012, 87, 2202-2210. [CrossRef] 
16. Kurt, A.; Kahyaoglu, T. Purification of glucomannan from salep: Part 1. Detailed rheological characteristics. Carbohydr. Polym. 2017, 168, 138-146. [CrossRef] [PubMed]

17. Zhou, Y.; Zhao, D.; Winkworth-Smith, C.G.; Foster, T.J.; Nirasawa, S.; Tatsumi, E.; Cheng, Y. Effect of a small amount of sodium carbonate on konjac glucomannan-induced changes in wheat starch gel. Carbohydr. Polym. 2015, 116, 182-188. [CrossRef]

18. Singh, V.; Sethi, R.; Tiwari, A. Structure elucidation and properties of a non-ionic galactomannan derived from the Cassia pleurocarpa seeds. Inte. J. Biol. Macromol. 2009, 44, 9-13. [CrossRef]

19. Yanuriati, A.; Marseno, D.W.; Harmayani, E. Characteristics of glucomannan isolated from fresh tuber of Porang (Amorphophallus muelleri Blume). Carbohydr. Polym. 2017, 156, 56-63. [CrossRef]

20. Lee, M.E.; Lee, H.D.; Suh, H.-H. Production and Characterization of Extracellular Polysaccharide Produced by Pseudomonas sp. GP32. J. Life Sci. 2015, 25, 1027-1035. [CrossRef]

21. Ma, L.; Chen, H.; Zhu, W.; Wang, Z. Effect of different drying methods on physicochemical properties and antioxidant activities of polysaccharides extracted from mushroom Inonotus obliquus. Food Res. Int. 2013, 50, 633-640. [CrossRef]

22. Wang, L.; Xu, H.; Yuan, F.; Fan, R.; Gao, Y. Preparation and physicochemical properties of soluble dietary fiber from orange peel assisted by steam explosion and dilute acid soaking. Food Chem. 2015, 185, 90-98. [CrossRef] [PubMed]

23. Tian, D.-T.; Li, S.-R.; Liu, X.-P.; Wang, J.-S.; Liu, C.-M. Synthesis and Properties of Konjac Glucomannangraft-poly(acrylic acid-co-trimethylallyl ammonium chloride) as a Novel Polyampholytic Superabsorbent. Adv. Polym. Technol. 2013, 32, E131-E140. [CrossRef]

24. Ahmed, Z.; Wang, Y.; Anjum, N.; Ahmad, H.; Ahmad, A.; Raza, M. Characterization of new exopolysaccharides produced by coculturing of L. kefiranofaciens with yoghurt strains. Int. J. Biol. Macromol. 2013, 59, 377-383. [CrossRef] [PubMed]

25. Lin, X.; Wu, Q.; Luo, X.; Liu, F.; Luo, X.; He, P. Effect of degree of acetylation on thermoplastic and melt rheological properties of acetylated konjac glucomannan. Carbohydr. Polym. 2010, 82, 167-172. [CrossRef]

26. Bardajee, G.R.; Hooshyar, Z. Novel potentially biocompatible nanoporous hydrogel based on poly ((2-dimethylaminoethyl) methacrylate) grafted onto salep: Synthesis, swelling behavior and drug release study. J. Polym. Res. 2013, 20. [CrossRef]

27. Yang, W.; Wang, Y.; Li, X.; Yu, P. Purification and structural characterization of Chinese yam polysaccharide and its activities. Carbohydr. Polym. 2015, 117, 1021-1027. [CrossRef]

28. Kurt, A.; Kahyaoglu, T. Rheological properties and structural characterization of salep improved by ethanol treatment. Carbohydr. Polym. 2015, 133, 654-661. [CrossRef]

29. Zhang, M.S.; Sun, L.; Zhao, W.C.; Peng, X.X.; Liu, F.Q.; Wang, Y.P.; Bi, Y.J.; Zhang, H.B.; Zhou, Y.F. Cholesteryl-Modification of a Glucomannan from Bletilla striata and Its Hydrogel Properties. Molecule 2014, 19, 9089-9100. [CrossRef]

30. Zeng, W.-C.; Zhang, Z.; Gao, H.; Jia, L.-R.; Chen, W.-Y. Characterization of antioxidant polysaccharides from Auricularia auricular using microwave-assisted extraction. Carbohydr. Polym. 2012, 89, 694-700. [CrossRef]

31. Chen, Y.; Mao, W.; Gao, Y.; Teng, X.; Zhu, W.; Chen, Y.; Zhao, C.; Li, N.; Wang, C.; Yan, M.; et al. Structural elucidation of an extracellular polysaccharide produced by the marine fungus Aspergillus versicolor. Carbohydr. Polym. 2013, 93, 478-483. [CrossRef] [PubMed]

32. Chen, Y.; Xie, M.-Y.; Nie, S.-P.; Li, C.; Wang, Y.-X. Purification, composition analysis and antioxidant activity of a polysaccharide from the fruiting bodies of Ganoderma atrum. Food Chem. 2008, 107, 231-241. [CrossRef]

33. Fan, D.; Ma, W.; Wang, L.; Huang, J.; Zhao, J.; Zhang, H.; Chen, W. Determination of structural changes in microwaved rice starch using Fourier transform infrared and Raman spectroscopy. Starch-Starke 2012, 64, 598-606. [CrossRef]

(C) 2018 by the authors. Licensee MDPI, Basel, Switzerland. This article is an open access article distributed under the terms and conditions of the Creative Commons Attribution (CC BY) license (http:/ / creativecommons.org/licenses/by/4.0/). 